\title{
O IPTU VERDE: PRÁTICAS SUSTENTÁVEIS TRAZEM BENEFÍCIOS FINANCEIROS À POPULAÇÃO
}

\author{
Letícia Thomasi Jahnke ${ }^{1}$ \\ Sheila Marione Uhlmann Willani ${ }^{2}$ \\ Tiago Luiz Rigon de Araújo ${ }^{3}$
}

\begin{abstract}
RESUMO
Atualmente, tem-se percebido cada vez mais a necessidade do equilíbrio entre meio ambiente e o meio urbano, visto que a qualidade de vida está relacionada ao meio em que se vive e para que se tenha uma vida efetivamente saudável se faz necessária a preservação e manutenção da mesma. Para isso traz-se a voga alguns exemplos de como tornar possível esta idéia a partir de políticas administrativas e culturais. Palavras-chave: Meio ambiente. Qualidade de vida. Sustentabilidade. IPTU verde.
\end{abstract}

\section{INTRODUÇÃO}

Através deste trabalho pretende-se expor a ligação e a necessidade do equilíbrio entre meio ambiente e meio social (meio ambiente nas áreas urbanas). Deste modo traz a voga o artigo 225 caput da Constituição Federal, que coloca como direito de todo brasileiro, um meio ambiente ecologicamente equilibrado, visto que este deve estar a disposição e cuidados de todos, indiscutivelmente.

Neste sentido coloca-se também a idéia de estímulo a esta cultura de preservação, tendo como objeto a redução do valor do imposto, chamado aqui por "IPTU verde", meio pelo qual se pode dar e alcançar a toda a população brasileira, um serviço e uma cultura de conservação, defesa, melhoria e recuperação deste, através do uso sustentável dos recursos naturais.

\footnotetext{
${ }^{1}$ Graduada em Direito pela Universidade Luterana do Brasil - ULBRA. Especialista em Processo Civil ULBRA. Especialista em Direito Civil - ULBRA. Mestranda em Direito pela Universidade Regional Integrada do Alto Uruguai - URI. Membro do Grupo de pesquisa de Direito e Sociobiodiversidade GPDS, da Universidade Federal de Santa Maria - UFSM.

${ }^{2}$ Atual mestranda e bolsista da Universidade Regional Integrada do Alto Uruguai e das Missões. Membro integrante do Projeto Cidadania e Direitos Culturais: A Proteção dos Direitos de Minorias nos Tribunais Brasileiros. Monitora do Grupo de Pesquisa em Mediação e Justiça Restaurativa. Mediadora.

${ }^{3}$ Graduado em Direito pela Universidade Luterana do Brasil - ULBRA. Mestrando em Direito pela Universidade Regional Integrada do Alto Uruguai - URI. Membro do Grupo de pesquisa de Direito e Sociobiodiversidade - GPDS, da Universidade Federal de Santa Maria - UFSM.
} 


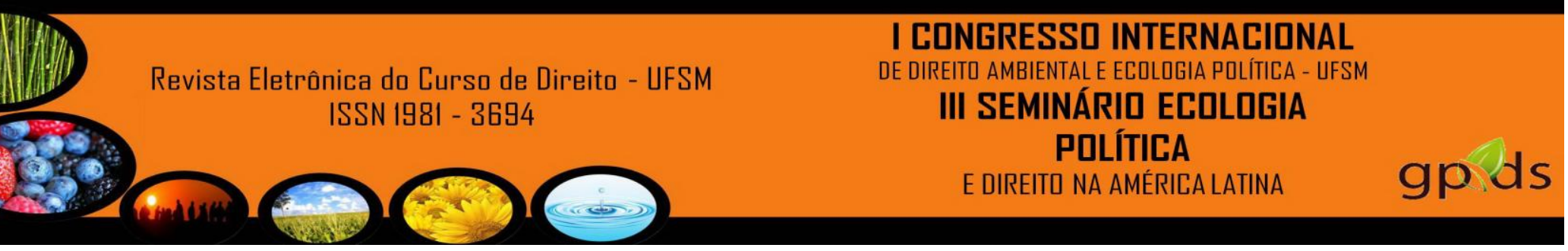

\section{Breves considerações acerca do meio ambiente}

Não há como não relacionar o Direito Ambiental ao Meio Ambiente. Os dois possuem uma correlação automática. Com base nos artigos inseridos na Constituição Federal, como preceitua o art. 225, caput:

Todos têm direito ao meio ambiente ecologicamente equilibrado, bem de uso comum do povo e essencial à sadia qualidade de vida, impondo-se ao Poder Público e à coletividade o dever de defendê-lo e preservá-lo para as presentes e futuras gerações. (BRASIL, 1988)

O meio ambiente pode vir a ser considerado um emaranhado de afinidades/repulsas entre o natural, o artificial e os seres vivos, com reflexos na vida e comportamento do indivíduo.

O conceito de meio ambiente deve ser amplo para José Afonso da Silva, "abrangente de toda a natureza, o artificial e original, bem como os bens culturais correlatos, compreendendo, portanto, o solo, a água, o ar, a flora, as belezas naturais, o patrimônio histórico, artístico, turístico, paisagístico e arquitetônico" (2004, p. 20).

Na Lei $n^{\circ}$ 6.938/81, que versa sobre a Política Nacional do Meio Ambiente, destaca-se no seu artigo $3^{\circ}$ que a conceituação de meio ambiente é "o conjunto de condições, leis, influências e interações de ordem física, química e biológica, que permite, abriga e rege a vida em todas as suas formas" (BRASIL, 1981).

A Constituição Federal de 1988 tratou de elencar em seu artigo 225 que "todos têm direito ao meio ambiente ecologicamente equilibrado, bem de uso comum do povo e essencial à sadia qualidade de vida, impondo-se ao Poder Público e à coletividade o dever de defendê-lo e preservá-lo para as presentes e futuras gerações” (BRASIL, 1988)

A subdivisão a cerca do meio ambiente é deliberada da seguinte forma:

- Elementos Naturais: solo, água, ar atmosférico, flora, fauna, enfim biosfera;

- Elementos Culturais: patrimônio artístico, histórico, turístico, paisagístico, arqueológico;

- Elementos Artificiais: edificações, ruas, tudo que engloba o espaço construído. (FERREIRA, 2000, p.22) 
Os elementos artificiais constituem a definição de meio ambiente artificial, ou seja, espaço urbano construído, edificações de maneira geral. Estando intimamente ligado ao conceito de cidade.

As cidades vêm se configurando um desafio árduo à estudiosos que buscam amenizar os problemas ambientais urbanos, buscando a melhora da qualidade de vida da população. Essa preocupação se tornou um campo interdisciplinar de discussões em busca de mecanismos capazes resguardar o meio ambiente.

Juntamente com o artigo 225 da Constituição Federal de 1988, o artigo 182 da mesma, seriam formas imediatas de determinar políticas relacionadas ao meio ambiente artificial.

Está elencado no artigo 182, que "a política de desenvolvimento urbano, executada pelo Poder Público municipal, conforme diretrizes gerais fixadas em lei, tem por objetivo ordenar o pleno desenvolvimento das funções sociais da cidade e garantir o bem-estar de seus habitantes" (BRASIL, 1988).

Através dessas definições, traz-se a baila, os também artigos constitucionais, $\operatorname{artigos} 5^{\circ}$ e $6^{\circ}$, pois conforme Celso Antônio Pacheco Fiorillo:

\begin{abstract}
a função social da cidade é cumprida quando esta proporciona a seus habitantes o direito à vida, à segurança, à igualdade, à propriedade e à liberdade (CF art. $5^{\circ}$, caput) bem como garante a todos um piso vital mínimo, compreendidos pelos direitos sociais à educação, à assistência dos desamparados entre outros encartados no art. $6^{\circ}$. (2003, p.225)
\end{abstract}

Deste modo é possível verificar que os indivíduos possuem a garantia, podendo-se dizer fundamental, ao bem-estar e a qualidade de vida, pois a cidade deve cumprir com sua função social a ela incumbida.

\title{
O desenvolvimento sustentável e as cidades brasileiras
}

A expressão "desenvolvimento sustentável” gera muita discussão a cerca de sua primeira utilização, mas acredita-se que fora utilizada em 1987, no Relatório Brundtland, elaborado pela Comissão Mundial sobre Meio Ambiente e Desenvolvimento, criado em 1984 pela Assembleia das Nações Unidas.

O Professor Ronaldo do Livramento Coutinho sintetiza desenvolvimento sustentável, sendo aquele que consegue harmonizar e compatibilizar qualidade de vida 
III SEMINÁRII ECOLOGIA

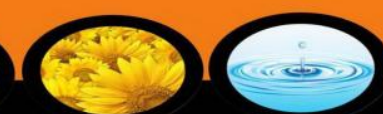

PRLÍTICA

E DIREITO NA AMÉRICA LATINA

desenvolvimento econômico-social com a preservação da qualidade do meio ambiente e do equilíbrio ecológico.” (art. 4 , I) (KRELL, 2008, p.31)

Assim, o objetivo é manter as bases do homem, para que as gerações futuras possam usufruir igualmente dos recursos os quais somos detentores nos dias de hoje. (FIORILLO e DIAFERIA, 1999, p.31)

A sustentabilidade é a união de ações humanas, relacionado com aspectos econômicos, sociais, culturais e ambientais. De uma forma mais evidente, consiste na exploração de áreas ou de uso de recursos naturais ou artificiais, de forma a evitar o prejuízo, ou causar o menor impacto possível, o equilíbrio entre o meio ambiente e a sociedade, juntamente com a biosfera que depende desse equilíbrio para existir.

Contudo há uma dificuldade em conciliar, unir o desenvolvimento e a sustentação do ambiente, parecem duas retas paralelas que nunca se cruzam. Pois a proteção ao meio ambiente estagnaria o desenvolvimento; e para se desenvolver é preciso devastar.

Nota-se a existência de um esgotamento nos moldes desenvolvimento econômico e industrial utilizados, e juntamente com isso houve uma grande devastação ambiental. (LEITE, 2000, p.22)

A crise ambiental atual enquadra a sociedade como uma sociedade de risco, na qual o modelo capitalista, com princípios basicamente financeiros é demasiadamente prejudicial ao meio ambiente. Deste modo "o modelo atual de vida é definido e difundido pelos meios de comunicação em massa como insustentável, comprometendo, no caso de sua manutenção, a continuidade das gerações futuras." (ARAÚJO e TYBUSCH, 2009, p.84)

Uma possibilidade de frear esse descaso é baseando-se no princípio do desenvolvimento sustentável, que como prevê a Magna Carta em seu art. 170, VI, está incluso no desenvolvimento econômico, permitindo o uso sustentável de recursos naturais. Salienta-se que:

Ao mesmo tempo, o desenvolvimento de um país (ou região) baseado em suas próprias potencialidades, isto é, endógeno, realizado de forma compatível com a gestão ecologicamente equilibrada. Além disso, este novo modelo de desenvolvimento seria lastreado por uma nova ética, na qual os objetivos econômicos seriam subordinados ao funcionamento dos sistemas naturais e aos parâmetros de qualidade de vida das pessoas. (COUTINHO, 2009, p.31) 
O desenvolvimento sustentável deve ser quantitativo, (não a qualquer preço), e qualitativo, buscando obter êxito na quantidade de um modo sustentável, não degradando, ou o mínimo possível, para que os recursos naturais possuam uma vida útil mais duradoura, que futuramente irá refletir economicamente em um custo menor, possibilitando um equilíbrio do meio ambiente.

A sustentabilidade econômica emoldura-se na esfera de medidas e políticas. São levados em consideração as diretrizes ambientais e sócio-económicos, criando assim, uma rede, onde cada variável esta interligada à outra.

Diante dessa ótica, o lucro não é considerado somente em caráter financeiro, mas também, no aspecto ambiental, uso correto de recursos naturias, sem a sua total degradação, baseado em uso sustentavelmente correto, atribuindo assim um valor economico aos elemetos naturais.

Fundamenta-se na estabilidade da sociedade, tanto sob o prisma de desenvolvimento social, como sócio-economica. Esta variável busca humanizar a economia.

Diante disso, foram acrescidos duas concepções em torno da sustentabilidade:

1) Agenda 21 - um plano que alcança todos os níveis governamentais de diferentes diversas extenções, onde verifica-se impactos no ambiente. Sintéticamente, é uma tentativa grandiosa de uma nova padronagem de desenvolvimento, baseada no desenvolvimento sustentável, conforme Andreas Krell:

Documento de fundamental importância, foi a Agenda 21, de natureza jurídica programática, cujo objetivo foi preparar o mundo para os desafios do século XXI e que foi chamada de "cartilha básica do desenvolvimento sustentável” social, enconomico e ambiental. (2008, p.32)

Ainda sobre a Agenda 21, Édis Milaré discorre:

“conjunto amplo e diversificado de diretrizes", as quais devem dar origem à elaboração de relatórios nacionais, agendas locais, cujas regras por sua vez, somente se tornarão obrigatórias na medida em que "letra e espírito" das propostas forem incorporadas em políticas e instrumentos legais federais, estaduiais e municipais. (2004, p. 67)

2) Metas de Desenvolvimento do Milénio (MDM) - tem início na Declaração do Milénio das Nações Unidas, em 2000. Nada mais é do que uma tentativa de fundir os diversos acordos internacionais efetuados em outros momentos em relação ao meio ambiente entre outros. É nestas metas que afirma que os governos não poupariam 
III SEMINÁRII ECDLOGIA

POLÍTICA

esforços para emancipar a população em geral daas condições sub-humanas da miséria, com prazo à ser cumprido. Esta meta, por exemplo, é medida pelo IDH, Índice de Desenvolvimento Humano, o qual une três grandezas: riqueza, educação e esperança média de vida.

Já a sustentabilidade ambiental incide na conservação de funções e integrantes do ecossistema, de caráter sustentável, sendo facultado a capacidade que o ambiente natural tem de manter a estrutura de vida para os indivíduos e os demais, qualidade de vida, o encanto do ambiente e a sua função como fonte de energia renovável.

Pode-se afirmar que a participação do cidadão é fundamental, pois é ele que sofre as consequências e, quanto maior asua participação mais democrática é a decisão (ARAÚJO e TYBUSCH, 2009, p.83). Sendo assim, as decisões e ações da população estão diretamente ligadas ao interesse em prevenir danos e proteger o meio ambiente.

A partir dessa visao acerca do desenvolvimento sustentável, adentra-se na esfera das cidades. A partir das duas últimas décadas do século $\mathrm{XX}$, a globalização tem trazido novas demandas para as cidades, sendo que a sustentabilidade urbana tem estado sob constante pressão.

As cidades estão buscando, cada vez mais, mecanismos para a real sustentabilidade ambiental, no caso urbana, a fim de que seus habitantes vivam de uma forma mais saudável.

Práticas como veículos movidos a hidrogênio, a melhora do meio de transporte público para que seja, efetivamente, mais utilizado, o uso de plano para reduzir as emissoes de $\mathrm{CO} 2$, incentivar construções ecologicamente corretas e também a busca por áreas verdes tantos no espaço público como no privado.

\section{O incentivo: IPTU Verde}

As áreas verdes estão sendo cada vez mais vistas nos centros urbanos. Um parque traz à população, além da beleza, proporciona a prática de esportes, além de todos os benefícios trazidos à saúde, tanto física quanto psicológica. Em Curitiba, no Paraná os

espaços de conservação, convício e lazer, essas áreas verdes passaram a fazer parte da cultura local. Elas permitem que cada cidadão se sinta conectado aos ciclos naturais, oferecendo um contraste com a paisagem artificial decorrente 
da urbanização do espaço ao longo do tempo. A par disso, resgatam a própria essência da formação das cidades que é oferecer a oportunidade do encontro entre pessoas. Constituem também, em nível local, indicadores da sustentabilidade dos processos naturais que possibilitam a continuidade da vida em suas diversas manifestações. (PREFEITURA DA CIDADE DE CURITIBA, 2012)

Deste modo, convence-se de que a área verde tem real importância na qualidade de vida da sociedade. Quando se trata de área verde em propriedades particulares, a questão se altera um pouco.

Muitos proprietários preferem ocupar todo o espaço do terreno para edificações, deixando a propriedade sem nenhuma área ou espaço verde. Pensando sob esta ótica e para incentivar a conservação ou a implantação dessas áreas, surgiu o IPTU Verde.

O IPTU (Imposto Predial e Territorial Urbano) é um imposto previsto no artigo 156 da Constituição Federal de 1988. Sendo de competência municipal instituir impostos sobre propriedade urbana, como um apartamento, sala comercial ou uma casa.

Com o intuito de incentivar o modelo sustentável surgiram projetos de Leis Municipais versando sobre a possível redução do IPTU quando forem constatadas práticas sustentáveis ou que promovam ações benéficas ao meio ambiente.

Alguns desses projetos de descontos integram Leis Municipais, como em Guarulhos (Lei $n^{\circ}$ 6.793/10), Curitiba (Lei $n^{\circ}$ 9.806/00), Sorocaba (Lei ${ }^{\circ}$ 9.571/11), Araraquara (Lei n 7.152/09), São Vicente (Lei n ${ }^{\circ}$ 634/2010) dentre outras cidades.

Na cidade de São Vicente, em São Paulo, o desconto se dá pela seguinte maneira:

O conceito é simples; proprietários que provarem que seu imóvel atende à critérios de sustentabilidade, recebem descontos de até $25 \%$ no Imposto Predial e Territorial Urbano (IPTU). Caso uma casa seja construída com tijolos ecológico, o proprietário recebe um desconto de $0,1 \%$, se mais de $15 \%$ do terreno mantiver áreas de solo permeáveis, são mais $0,07 \%$. Ao todo são 22 critérios que ajudam da redução do consumo de água, energia e resíduos.Para solicitar o desconto, basta o contribuinte procurar a Secretaria de Meio Ambiente (SMA) do seu município, agendar e protocolar o pedido de vistoria. (PALESTRA, 2011)

Já em Guarulhos, o desconto está exposto no artigo 61, da Lei 6.793/10 é de:

Será concedido desconto de até no máximo $20 \%$ (vinte por cento) no valor do Imposto sobre a Propriedade Predial e Territorial Urbana - IPTU anual devido, pelo período de cinco exercícios consecutivos contados a partir do exercício seguinte ao da efetiva implantação ou no caso de imóveis que já tenham adotado 
as medidas ambientais na data da publicação da presente Lei, a partir do exercício seguinte ao da comunicação ao órgão fazendário, para os imóveis edificados que adotem duas ou mais medidas a seguir enumeradas:

I - sistema de captação da água da chuva: $3 \%$ (três por cento) de desconto;

II - sistema de reuso de água: $3 \%$ (três por cento) de desconto;

III - sistema de aquecimento hidráulico solar: $3 \%$ (três por cento) de desconto;

IV - sistema de aquecimento elétrico solar: 3\% (três por cento) de desconto; $\mathrm{V}$ - construções com material sustentável: $3 \%$ (três por cento) de desconto;

VI - utilização de energia passiva: $3 \%$ (três por cento de desconto;

VII - sistema de utilização de energia eólica: 5\% (cinco por cento) de desconto;

VIII - instalação de telhado verde, em todos os telhados disponíveis no imóvel para esse tipo de cobertura: 3\% (três por cento) de desconto;

IX - separação de resíduos sólidos, benefício a ser concedido exclusivamente aos condomínios horizontais ou verticais, e que, comprovadamente, destinem sua

coleta para reciclagem e aproveitamento: $5 \%$ (cinco por cento) de desconto. (GUARULHOS, 2010)

Já em Curitiba, no ano de 2012 dos "544 mil imóveis, aproximadamente 107 mil terão algum tipo de desconto ou isenção total. No próprio carnê que o contribuinte receber virá a informação de quanto é o desconto e o motivo da redução.” (CURITIBA, 2011)

Com isso, entende-se que "a preservação, conservação, defesa, melhoria, recuperação, uso sustentável dos recursos naturais" (MORAES, 2009, p.7-8) e controle do meio ambiente proporciona uma melhora na qualidade de vida dos indivíduos, incentivados pela redução no valor do imposto, com base nas práticas de sustentabilidade.

Nos moldes da sociedade atual, com o alto consumismo, com a busca incessante pelo conforto, é de suma importância que essa consciência ambiental seja implantada na cultura dos cidadãos, pois para manter-se a sociedade que se tem é preciso mudar. Para que não haja um maior decréscimo na qualidade de vida de vida.

\section{CONSIDERAÇÕES FINAIS}

Conforme supra mencionado, os moldes da sociedade atual se apresentam em alto nível de consumismo, numa busca incessante pelo conforto, desta forma é que se entrelaça o meio ambiente a qualidade de vida.

Entende-se que a preservação ambiental se faz necessária e que o uso sustentável dos recursos naturais é uma das melhores saídas para tanto. Desta forma se 


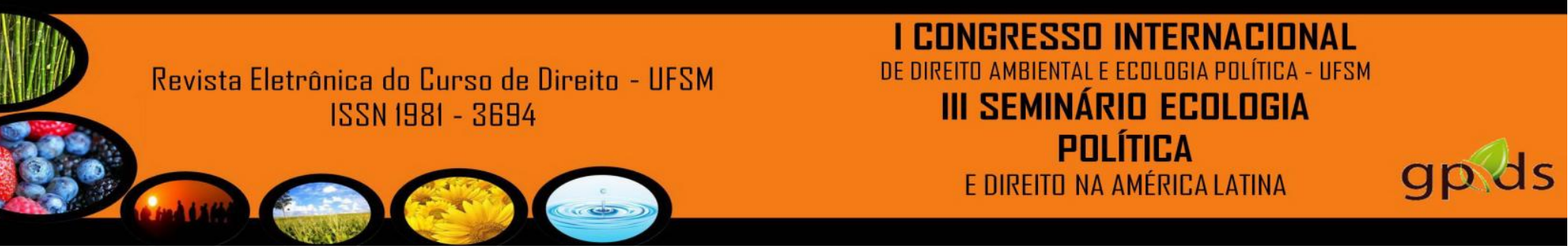

poderá alcançar o equilíbrio entre meio ambiente e meio social, não prejudicando o primeiro, mas sim aliando-o as necessidades do segundo e que deste modo, proporciona-se-à uma melhora na qualidade de sobrevida de ambos.

Contudo, registra-se que o incentivo da redução no valor do imposto pode servir sim de estímulo para a efetivação da cultura de equilíbrio entre meio ambiente e meio social, mas que mais ainda com base nas práticas de sustentabilidade, de conscientização e de uma verdadeira e efetiva cultura de "ambiente saudável $=$ ser humano saudável".

\section{REFERÊNCIAS BIBLIOGRÁFICAS}

ARARAQUARA. Lei $\mathbf{n}^{\mathbf{7}}$ 7.152/09. Diponível em: <http://www.leismunicipais.com.br/cg i-local/showinglaw.pl>. Acesso em 05 set. 2012.

ARAÚJO, Luiz Ernani Bonesso. Tybusch, Jerônimo Siqueira. PES, João Hélio Ferreira (coord.). Direito Ambiental contemporâneo: prevenção e pracaução. Curitiba: Juruá, 2009, p.84.

BRASIL. Constituição Federal de 1988. Disponível em $<$ http://www.planalto. gov.br/ccivil_03/constituicao/constitui\%C3\%A7ao.htm>. Acesso em 05 set. 2012.

Lei 6.938/1981. Diponível em: <http://www.planalto.gov.br/ccivil_03/leis /L69 38.htm>. Acesso em 05 set. 2012.

CARRERA, Francisco. SÉGUIM, Elida. Planeta Terra: uma abordagem de direito ambiental. $2^{\text {a }}$ ed. Rio de Janeiro: Lúmen Júris, 2001

COUTINHO, Ronaldo do Livramento. In: COUTINHO, Ronaldo do Livramento.

ROCCO, Rogério. (orgs.). O Direito Ambiental das Cidades. $2^{\mathrm{a}}$ ed. Rio de Janeiro: Lúmen Júris, 2009.

CURITIBA. Preservação de área verde dá desconto no IPTU. Diponível em: < http:// www.curitiba.pr.gov.br/noticias/preservacao-de-area-verde-da-desconto-noiptu/21592>. Acesso em 05 set. 2012.

FERREIRA, Luiz Pinto. O meio ambiente, os Crimes e os Danos Ecológicos. Revista do Instituto dos Advogados de Pernambuco, v.1 n.2, 2000.

FIORILlo, Celso Antonio Pacheco. Curso de Direito Ambienta Brasileiro. São Paulo: Saraiva, 2003. 


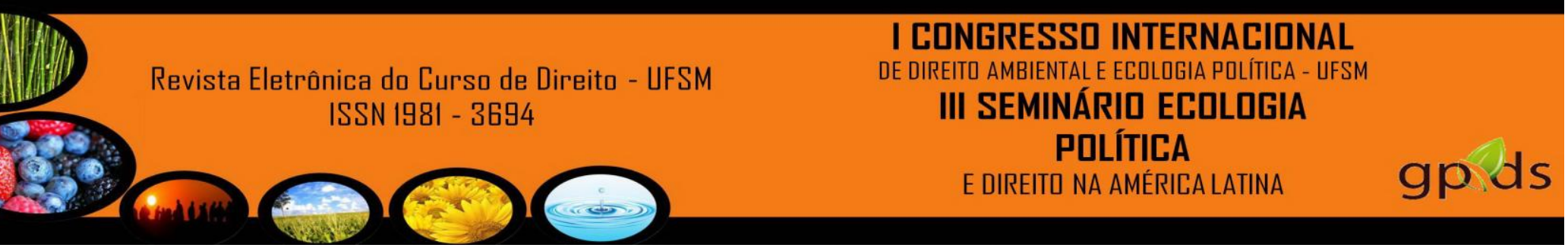

FIORILlO, Celso Antônio Pacheco e DIAFÉRIA, Adriana. Biodiversidade e patrimônio genético no direito ambiental brasileiro. São Paulo. Ed.: Max Limonad. 1999.

GUARULHOS. Lei no 6.793/10 . Disponível em: http://www.leismunicipais.com. br/le gislacao-de-guarulhos/1394041/lei-6793-2010-guarulhos-sp.html. Acesso em 05 set. 2012.

KRELL, Andréas Joachim. Desenvolvimento sustentável às avessas nas prais de Maceió/AL: a liberação de espigões pelo novo código de urbanismo e edificações. Maceió: UFAL, 2008

MILARÉ, Édis. Direito do Ambiente: doutrina, jurisprudência, glossário. São Paulo: RT, 2004.

PALESTRA. IPTU Verde. Disponível em: <http://www.palestrasustentabilidade.

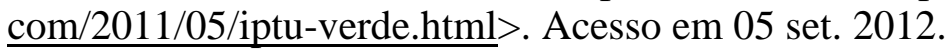

PREFEITURA DA CIDADE DE CURITIBA. Biocidade. Disponível em: <http://www.biocidade. curitiba.pr.gov.br/biocity/49.html >. Acesso em 05 set. 2012.

SILVA, José Afonso da. Direito ambiental constitucional. 5. ed. São Paulo: Malheiros, 2004.

SOROCABA. Lei $\mathbf{n}^{\mathbf{0}}$ 9.571/11. Disponível em: < http://www.leismunicipais.com.br / twitter/322/legislacao/lei-9571-2011-sorocaba-sp.html>. Acesso em 05 set. 2012. 